\title{
MIELKEANTHIDIUM, GEN.N. DE DIANTHIDIINI DA AMÉRICA DO SUL (HYMENOPTERA, MEGACHILIDAE) ${ }^{1}$
}

\author{
Danúncia Urban ${ }^{2}$
}

\begin{abstract}
MIELKEANTHIDIUM, GEN.N. OF SULAMERICAN DiANTHIDIINI (HYMENOPTERA, Megachilidae). Mielkeanthidium, gen.n. with long preepisternal carina on the mesepisternum is proposed for two species from Southern Brazil: Mielkeanthidium nigripes, sp.n. and Mielkeanthidium rubripes, sp.n. The females are characterized by the absence of the arolia and of the subbasal tooth of the mandibles, the males by the two large carinated lobes on the apical tergum.

KEY WORDS. Apoidea, Megachilidae, Anthidiinae, Mielkeanthidium, taxonomy
\end{abstract}

Mielkeanthidium, gen.n. pertence ao grupo de gêneros de Dianthidiini com carena pré-episternal longa e dimorfismo quanto aos arólios, presentes nos machos e ausentes ou reduzidos nas fêmeas. O material tipo está depositado na Coleção de Entomologia Pe. J.S. Moure, Departamento de Zoologia da Universidade Federal do Paraná (DZUP); no Laboratório de Pesquisas Biológicas da Pontifícia Universidade Católica do Rio Grande do Sul (PUCRS); e no Museu de Ciências Naturais da Fundação Zoobotânica do Rio Grande do Sul (FZB).

\section{Mielkeanthidium, gen.n.}

Espécie tipo. Mielkeanthidium nigripes, sp.n.

Macho com o tegumento brilhante denso-pontuado. Mandíbulas tridenteadas, os dentes equidistantes, sendo o mediano o menor, com carena lateral externa baixa e larga, arqueada, separando a base da mandíbula, brilhante e com pontos grandes alongados, da parte apical um pouco inflada e com pontos menores esparsos; a carena externa inferior quase até o meio da mandíbula; palpos maxilares biarticulados, sem pêlos longos apicais; clípeo abaulado, deprimido no ápice, com tubérculos na margem que sobressai ao labro; suturas subantenais quase retas, convergindo para a sutura epistomal; carenas interalveolares curtas e laminadas, arqueadas, a lâmina voltada para os lados e encobrindo parte dos alvéolos; distância entre as carenas interalveolares pouco maior que seu comprimento; sem carena frontal; carenas paroculares completas; carena hipostomal forte e laminada; sem carena pré-ocipital; antenas com o escapo pouco mais longo que a distância interalveolar; flagelômeros curtos ou igualando seu diâmetro, o apical mais longo.

1) Contribuição número 926 do Departamento de Zoologia, Universidade Federal do Paraná.

2) Departamento de Zoologia, Universidade Federal do Paraná, Caixa Postal 19020 , 81531-990 Curitiba, Paraná, Brasil. 
Pronoto com lâmina translúcida nos lobos, arqueada e um pouco voltada para a frente terminando bem antes do mesoscuto; mesepisternos com carena pré-episternal longa, quase alcançando o discrímen mesepisternal; mesoscuto tão longo quanto largo ao nível das tégulas, expandido lateralmente em lâmina curta voltada para cima; tégulas com o bordo lateral estreitamente voltado para cima na metade posterior; escutelo deprimido e brilhante na base entre as axilas, arredondado posteriormente com lamelas translúcidas laterais e emarginação mediana, sobressaindo ao metanoto; axilas carenadas, não projetadas para trás; asas anteriores com a bifurcação entre a média e o cúbito coincidindo ou pouco anterior à cúbito-anal; asas posteriores com o lobo jugal aproximadamente um terço do anal; coxas posteriores com cerdas curtas e grossas de ápice arredondado, na face proximal; esporões tibiais normais; com arólio entre as garras nas pernas anteriores e medianas, os arólios reduzidos nas posteriores; propódeo vertical com base foveolada, as fovéolas menores no meio; espiráculo propodeal com larga área posterior brilhante levemente trabeculada e com carena.

Primeiro tergo com carena fraca separando a parte anterior da dorsal, a carena desaparecendo aos lados; depressão marginal estreita nos flancos do primeiro ao quarto tergo; quinto tergo quase vertical, com depressão marginal completa, mais rasa e mais larga no meio; sexto tergo abaulado, com a metade distal voltada para a frente, fortemente deprimido para o ápice e com estreita lâmina apical projetada; quinto e sexto tergos com lóbulos látero-apicais projetados para trás que se encaixam quando em repouso; sétimo tergo voltado para a frente, sem depressões látero-discais, com dois lobos laterais largos e carenados voltados para baixo e perpendiculares aos esternos. Esterno basal com carena mediana alta e laminada no terço basal, subapicalmente inflado e com margem larga no plano inferior; segundo esterno um pouco inflado no disco, mais curto que um terço da sua largura, com franja apical tão longa como o diâmetro do ocelo, quando em repouso encobrindo alguns esternos porém deixando visível o distal; terceiro esterno com o bordo levemente bissinuoso, canaliculado no meio, ao longo do comprimento; quarto e quinto esternos com o bordo chanfrado no meio; o quarto esterno com depressão mediana ao longo do comprimento, a depressão alargando para o ápice, tendo na metade distal uma projeção esclerotizada triangular elevada e com cerdas apicais de tamanho uniforme, ápice arredondado, levemente arqueadas para o esterno e justapostas; flancos do quarto e quinto esternos projetados em lobos laterais com duas carenas: a ventral arqueada avançando até a base do esterno e a carena dorsal só na metade apical, as duas unidas formando um $\mathrm{Y}$ invertido; sexto esterno voltado para baixo e com o bordo simples, dobrado em ângulo reto nos flancos.

Fêmea semelhante ao macho. Difere nas seguintes estruturas: Mandíbulas com dois dentes apicais separados do basal por amplo recorte quase reto; com pontos grandes alongados na metade basal; carena lateral externa baixa e larga, até pouco além do meio, a carena externa inferior um pouco menor. Sem arólio entre as garras. Primeiro ao quinto tergo com depressão subapical estreita nos flancos; sexto tergo deprimido subapicalmente.

Comentário. Mielkeanthidium tem em comum com Hypanthidioides Moure, 1947 e Dicranthidium Moure \& Urban, 1975, a carena pré-episternal muito longa, quase alcançando o discrímen. 
Fêmeas de Hypanthidioides e de Dicranthidium têm quatro dentes mandibulares; o macho tem os flagelômeros mais longos que seu diâmetro, exceto o basal; o sétimo tergo de Dicranthidium tem duas projeções digitiformes fortemente voltadas para a frente e sobrepostas ao ápice do segundo esterno, este quase igualando a metade da sua largura; em Hypanthidioides o sétimo tergo é quase reto, sem lobos apicais, deixando visiveis todos os esternos.

O nome do gênero é uma homenagem ao Prof. Dr. Olaf H.H. Mielke por sua dedicação ao estudo dos Lepidoptera.

\section{Mielkeanthidium nigripes, sp.n.}

Fig. 1

Diagnose. Tergo basal com faixa amarela; escutelo preto; vértice com faixas laterais amarelas. Macho com os lobos laterais do sétimo tergo quase igualando o dobro da largura do recorte mediano.

Holótipo macho. Tegumento preto; clípeo amarelo com orla preta, mais larga junto às fóveas tentoriais e com duas projeções pequenas partindo do ramo horizontal da sutura epistomal; mandíbulas com área subapical castanha; paroculares largamente amarelas junto ao clípeo, o amarelo diminuindo em direção aos olhos e terminando pouco acima dos alvéolos antenais; duas faixas longitudinais interalveolares amarelas, pouco maiores que as carenas interalveolares; metade posterior do vértice com faixas laterais amarelas estreitas, afastadas no meio por uma distância maior que a interocelar. Mesoscuto com faixas amarelas látero-basais, um pouco mais largas para o meio; tégulas castanho-amareladas com nódoa amarela sub-basal em arco acompanhando o bordo anterior; pernas anteriores e medianas amareloacastanhadas na face anterior das tíbias e parte apical dos fêmures; nas tíbias anteriores com amarelo na face dorsal. Primeiro, terceiro, quarto e quinto tergos com faixa amarela discal larga, a do quinto com o contorno irregular no bordo posterior; segundo tergo com nódoas amarelas laterais e uma pequena nódoa amarela discal na metade esquerda; sexto tergo com nódoas castanhas nos flancos; sétimo amarelo-acastanhado subapicalmente nos lobos; primeiro e segundo esternos pretos, do terceiro ao quinto esterno amarelo-acastanhado, ápice do quinto e o sexto esterno castanhos; estrutura esclerotizada preta no meio do quarto esterno.

Comprimento aproximado $6,83 \mathrm{~mm}$; comprimento da asa anterior, a partir do esclerito costal, $6,67 \mathrm{~mm}$; largura da cabeça $2,60 \mathrm{~mm}$; comprimento do olho $1,70 \mathrm{~mm}$; distância interorbital superior $1,56 \mathrm{~mm}$ e a inferior $1,30 \mathrm{~mm}$.

Variação. Um parátipo com faixa amarela completa no segundo tergo, estreita e mais para trás nos cantos, e pequenas nódoas amarelas nos flancos do sexto tergo.

Alótipo fêmea. Cabeça e mesosoma quase pretos, estria parocular amarela estreita e mais curta que o escapo, na região mediana; metade posterior do vértice com faixas laterais amarelas estreitas, separadas por uma distância quase igual à interocelar; antenas com pouco castanho, predomina o enegrecido. Base do mesoscuto com faixas laterais amarelas estreitas; tégulas castanhas; pernas com castanho 
na face anterior das tíbias anteriores. Primeiro, terceiro, quarto e quinto tergos com faixa amarela discal, a faixa mais estreita no meio e nos cantos; segundo tergo com nódoas laterais amarelas.

Comprimento aproximado $7,75 \mathrm{~mm}$; comprimento da asa anterior a partir do esclerito costal $6,25 \mathrm{~mm}$; largura da cabeça $2,52 \mathrm{~mm}$; comprimento do olho $1,70 \mathrm{~mm}$; distância interorbital superior $1,62 \mathrm{~mm}$ e a inferior $1,32 \mathrm{~mm}$.

Holótipo macho. BRASIL, Santa Catarina: Lages, 30.XII.1991, D.T. Santos leg.; alótipo fêmea com a mesma etiqueta do holótipo, depositados na Coleção Pe. J.S. Moure (DZUP). Parátipos do Rio Grande do Sul, Canela, 28.I.1992, M. Hoffmann leg., um macho e uma fềmea, depositados na Fundação Zoobotânica (FZB); S.Francisco de Paula, 6.II.1985, D.Wittmann leg. um macho, depositado no Laboratório de Pesquisas Biológica (PUCRS).

Distribuição geográfica. BRASIL: Santa Catarina e Rio Grande do Sul. Etimologia. Nome alusivo ao colorido predominante das pernas.
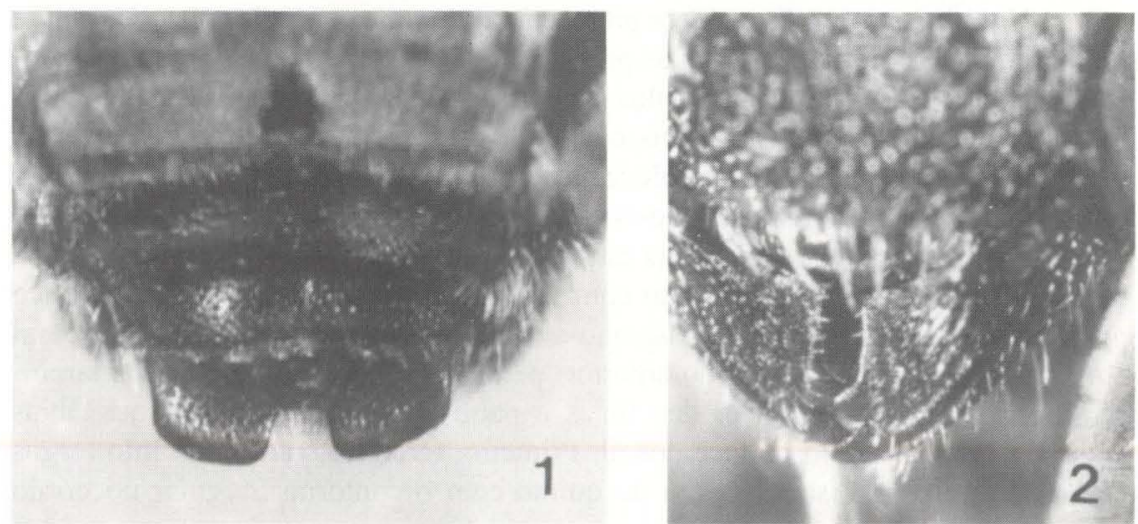

Figs 1-2. (1) Esternos distais e face ventral do sétimo tergo do macho de Mielkeanthidium nigripes, sp.n.; (2) parte da cabeça da fêmea de Mielkeanthidium rubripes, sp.n. evidenciando a margem cortante das mandibulas.

\section{Mielkeanthidium rubripes, sp.n.}

Fig. 2

Diagnose. Faixa amarela do tergo basal interrompida no meio; escutelo com margem amarela; nódoas arredondadas amarelas no vértice, atrás dos olhos. Macho com o recorte mediano do sétimo tergo igualando a largura dos lobos laterais.

Holótipo macho. Tegumento predominante preto; clípeo amarelo com ápice preto, mandíbulas manchadas subapicalmente com castanho; mancha amarela das áreas paroculares muito larga junto ao clípeo, estreitando bruscamente em arco, e terminando na altura do limite dorsal das faixas longitudinais interalveolares 
também amarelas, estas curtas e incluindo as carenas interalveolares; antenas amarelo-acastanhadas ventralmente e no dorso do primeiro ao quinto flagelômero, no restante castanho-enegrecidas; metade posterior do vértice com duas nódoas amarelas arredondadas, atrás dos olhos. Base do mesoscuto com duas faixas amarelas laterais, mais largas no disco e estreitando muito para os lados; escutelo com margem amarela; tégulas castanho-amareladas com nódoa amarela subapical formando um círculo; pernas com os artículos basais enegrecidos, parte dos fêmures, as tíbias e os tarsos amarelo-ferrugíneos, as tíbias posteriores com nódoa discal preta no lado dorsal. Tergo basal com duas faixas látero-discais amarelas largas, separadas no meio por distância inferior a meio diâmetro de flagelo; segundo com nódoas laterais amarelas pequenas; terceiro ao sexto tergo com faixa amarela discal larga só na parte dorsal, a faixa prolongada para os lados em estria muito fina acastanhada, fracamente bissinuosa no terceiro; sétimo tergo com larga faixa subapical amarela e orla castanha; esterno basal e parte do segundo pretos, com larga orla castanha no segundo; terceiro ao quinto esterno com o amarelo levemente acastanhado, sexto esterno castanho.

Comprimento aproximado $6,50 \mathrm{~mm}$; comprimento da asa anterior a partir do esclerito costal 4,80 mm; largura da cabeça $2,22 \mathrm{~mm}$; comprimento do olho $1,46 \mathrm{~mm}$; distância interorbital superior $1,40 \mathrm{~mm}$ e a inferior $1,12 \mathrm{~mm}$.

Alótipo fềmea. Mesosoma e tergo basal como no macho. Região mediana das paroculares com estria amarela curta e estreita, ocupando uma área menor que o escapo; metade posterior do vértice com faixas laterais amarelas estreitas, separadas por uma área maior que a distância entre os ocelos laterais. Terceiro ao quinto tergo com faixa amarela larga só no dorso.

Comprimento aproximado $6,00 \mathrm{~mm}$; comprimento da asa anterior a partir do esclerito costal $4,80 \mathrm{~mm}$; largura da cabeça $2,40 \mathrm{~mm}$; comprimento do olho $1,52 \mathrm{~mm}$; distância interorbital superior $1,52 \mathrm{~mm}$ e a inferior $1,20 \mathrm{~mm}$.

Holótipo macho. BRASIL, Rio Grande do Sul: Lavras do Sul (Rincão do Inferno), 11.XII.1991, C. Schlindwein leg. . Alótipo fêmea com a mesma etiqueta de procedência. Depositados na Coleção Pe. J.S. Moure (DZUP).

Distribuição geográfica. BRASIL: Rio Grande do Sul.

Etimologia. Nome alusivo à cor predominante das pernas.

AGRADECIMENTOS. A autora agradece ao Prof. Dr. Albino Morimasa Sakakibara pelas fotos que ilustram este trabalho.

\section{REFERÊNCIAS BIBLIOGRÁFICAS}

Moure, J.S. 1947. Novos agrupamentos genéricos e algumas espécies novas de abelhas sulamericanas. Publ. Avuls. Mus. Paranaense 3: 1-37.

Moure J.S. \& D. UrBan. 1975. Dicranthidium novo subgênero de Hypanthidioides Moure, 1947 (Hymenoptera, Apoidea). Rev. Brasil. Biol. 35 (4): 837-842.

Recebido em 30.I.1996; aceito em 01.VIII.1996. 